\title{
Analysis Report on the Employment Quality of the First Graduates of Preschool Education in Local Colleges---A Case Study of Shaanxi Xueqian Normal University
}

\author{
Ming Fan \\ Shaanxi Xueqian Normal University, Xi'an, Shaanxi, 710061
}

Keywords: Transformation and development, local colleges and universities, pre-school education, the first undergraduate, employment quality.

\begin{abstract}
In order to alleviate the rapid development of pre-school education in the process of lack of teachers, as one of the important initiatives in Shaanxi Province, in March 2012, the Ministry of Education and the Shaanxi Provincial People's Government approved the original Shaanxi Institute of Education changed its name to Shaanxi pre-school teacher, And in September that year began to recruit the first batch of undergraduate students. After four years of training, through the first 720 undergraduate graduates to track the employment situation found that graduates of the overall quality of employment is higher, in line with the school based in Shaanxi, the service location, the work unit is relatively stable nature, after the basic employment Rights and interests are guaranteed. And graduates of the job and the professional relevance of the high relevance of the employment of strong adaptability of graduates to carry out the work of the school more effective recognition, but due to the impact of wages and other aspects of the job satisfaction Room for improvement. As the local colleges and universities with the characteristics of pre-school education reform, the author analyzes and evaluates the quality of their first undergraduates' employment, and accumulates valuable experience for the continuous improvement of the training and supplementary mechanism of kindergarten teachers.
\end{abstract}

\section{Introduction}

In recent years, Shaanxi attaches great importance to the development of pre-school education, according to the "pre-school education in Shaanxi Province Research Report" [1], by the end of 2010, the province engaged in early childhood education staff of a total of 48559 (not including executive leadership and ground Personnel), according to "Shaanxi Province," second five "population development special plan" [2] proposed the province's average annual birth rate of $10 \%$ calculation (average annual population growth rate of $6 \%$ below), "second five" Period, the province's total population will continue to grow at an average annual rate of 200,000. According to the Shaanxi Provincial Health Commission statistics, the province will add more than 50,000 children each year, and the implementation of the national "two children policy" since the newborn children there are increasing trend. According to the above data, Shaanxi Province in the "second five" (2011-2015) period, a total of 29207 pre-school teachers to be added, the average annual need to add 5841 teachers [3], pre-school teachers is particularly inadequate problem.

In order to alleviate this problem, as one of the important initiatives in Shaanxi Province, in March 2012, the Ministry of Education and the Shaanxi Provincial People's Government approved the original Shaanxi Institute of Education changed its name to Shaanxi pre-school teacher, in the opening of more than 30 years of pre-school education On the basis of this as an opportunity to embark on the characteristics of the development of the road, in September that year began to recruit the first batch of undergraduate students. Especially in 2014, Shaanxi Province was identified as the transformation of the development of pilot institutions, pre-school education is gradually formed its own professional construction features: to cultivate the practice of "general" kindergarten teachers as the basic goal, comprehensive Carrying out the "school - land - garden" 
cooperative education personnel training mode. After four years of careful training, 2016 first 720 undergraduate students smooth employment, for the development of early childhood education in Shaanxi Province into the new force. Some scholars have pointed out that "employment is the livelihood of the country ... especially as the most dynamic young students, carrying the knowledge innovation, social progress of the task, the quality of employment is a test of a country's higher education level of important indicators, but also Directly related to the sustainable development of social economy. "[4] In order to understand the overall employment of the first graduates, the school conducted two follow-up survey, respectively, at the end of 2016 for the employment of graduates to follow the survey, and 2017 May For the follow-up survey of the evaluation of the graduates, the quality analysis report is formed on this basis.

\section{The basic situation of graduates}

Health distribution: mainly in Shaanxi students. As a result of Shaanxi pre-school teacher college is sponsored by the Shaanxi Provincial People's Government, Shaanxi Province Department of Education in charge of the full-time public province of ordinary undergraduate colleges, its school located in the "based in Shaanxi, service place", therefore, in pre-school education 2016 The total number of graduates in Shaanxi Province is 651, accounting for $90.42 \%$ of the total number of graduates, 69 from other provinces, from Henan, Shanxi, Hebei, Jiangxi, Fujian, Xinjiang, Shandong, Guizhou, Shandong, Anhui, Gansu , Hubei and other provinces, autonomous regions, accounting for $9.58 \%$ of the number of graduates. In the Shaanxi province, the number of students in the Guanzhong area was 328, accounting for 50.38\%. In the south of Shaanxi Province, 200 people accounted for 30.72\%. The number of students in northern Shaanxi was 123 and 18.89\%.

Gender distribution: girls occupy the vast majority. As the school long-term teacher education for the development of characteristics, combined with pre-school education graduates after the employment characteristics of the work, in the admissions, training process, girls and more boys, and girls occupy the vast majority. 720 graduates, girls 684 people accounting for $95 \%$ of the total number of boys and only 36 people accountings for $5 \%$ of the total number.

Ethnic distribution: the majority of Han students. Shaanxi Province, mainly in the northwest of China, but most of the students from Shaanxi Province, Shaanxi Province, the Han population, therefore, the first undergraduate Han graduates 715 , accounting for $99.31 \%$; minority graduates only 5, of which Hui 4 people, Zhuang one person, a total of $0.69 \%$ of the total number.

As of the end of June 2016 digital statistics, 2016 session of 720 undergraduate students signed an agreement 651 (by the Shaanxi Provincial Department of Education audit), Kaoran 24, the number of employed 675 people, the initial employment rate of $95.88 \%$; by the end of December 2016, Signed the employment agreement 680 people, college entrance examination 25, the number of employment 705 people, the employment rate of $97.99 \%$. As shown in Table 1:

Table 1: 2016 session of the undergraduate graduates employment rate statisticsv

\begin{tabular}{|c|c|c|c|c|c|}
\hline 2012 & Total & Signed & Post & Total Signed & employment rate \\
\hline Until 2012/06 & 720 & 651 & 24 & 675 & $95.88 \%$ \\
\hline Until 2012/12 & 720 & 680 & 25 & 705 & $97.92 \%$ \\
\hline
\end{tabular}

The nature of employment: the main kindergarten. According to the end of 2016 statistics show that 2012 ordinary undergraduate graduates in 680 people signed employment agreement, 25 people admitted to domestic and foreign university graduate students, into kindergarten work a total of 315 people (including public kindergarten 131 people, private kindergarten 184 people, accounting for graduates The total number of $43.75 \%$ ), access to other institutions 35 people employed, into the primary and secondary school employment 39 people, into the state-owned enterprises employed 18 people, into the private sector (mainly educational institutions, etc.) 258 , the other 15 , flexible employment 15 The

In the graduates, in addition to most of the entry into the kindergarten (public, private) work, there are some students through the recruitment test, special staff teacher plan, revitalization plan, 
etc., choose to primary and secondary schools, administrative institutions, education departments, business units Such as employment. According to statistics, through the recruitment test admission 73 people, public kindergarten 70 people, public primary school 2, secondary school 1; institutions recruitment examination admission 14 people, are in public kindergarten; special postgraduate admission of 37 people, public kindergarten 29 people, public primary school 8; revitalization plan admission 10 people, public kindergarten 8 people, public primary school 2 people.

Employment geographical distribution: the majority of Guanzhong area. As a result of pre-school education students mainly from Shaanxi Province, therefore, of the 680 registered graduates, $91.5 \%$ of the graduates choose to work in the province, especially in Guanzhong area, 497 jobs, accounting for $73.1 \%$; 57 people in southern Shaanxi, accounting for 8.4\%; employment in northern Shaanxi 68 People, accounting for $10 \%$. The number of graduates who choose to work outside the province is only 58, accounting for $8 \%$ of the total number of graduates. 2016 graduates of the employment unit of the classification of the status of Table 2:

Table 2: Pre-school education department 2016 graduates employment location distribution listv

\begin{tabular}{|l|l|l|l|l|l|l|}
\hline \multirow{2}{*}{$\begin{array}{l}\text { number of } \\
\text { people }\end{array}$} & \multirow{2}{*}{$\begin{array}{l}\text { Signed } \\
\text { Number }\end{array}$} & \multicolumn{3}{|l|}{ Signed Location } & \multicolumn{2}{|l|}{ Shaanxi } \\
\cline { 4 - 6 } & & & $\begin{array}{l}\text { Guanzhong } \\
\text { area }\end{array}$ & $\begin{array}{l}\text { Southern } \\
\text { Shaanxi }\end{array}$ & $\begin{array}{l}\text { Northern } \\
\text { Shaanxi }\end{array}$ & Others \\
\hline 2016 & 720 & 680 & 497 & 57 & 68 & 58 \\
\hline
\end{tabular}

\section{The quality of employment analysis of graduates}

The employment rate of college graduates has been widely concerned by the community, and even become an important indicator of evaluation of government and university employment [5]. But there are also scholars that employment is related to two "quantity": one is the number of jobs, one is the quality of employment [6]. Therefore, in order to understand the quality of the employment of the first undergraduate graduates, the end of 2016, based on the "Internet +" technology, pre-school education professional use of mobile micro-credit platform, 2016 graduates quality tracking survey. The whole survey questionnaire covers 15 related dimensions, 47 projects, such as the geographical, nature, job information, job and professional degree, monthly average income, replacement job status and so on. Of the 720 fresh graduates, 512 students received information feedback, accounting for $71.1 \%$ of the total number. The results of this survey provided a scientific basis for the analysis of the quality of employment of graduates.

In order to understand the comprehensive quality of employment of graduates, the questionnaire set up the "employment destination", "the nature of the work unit", "work unit area" and "personnel relationship type" and other dimensions. Through the statistical analysis of the micro-feedback information of the mobile phone, the graduates have basically completed the employment, and the nature of the work unit is relatively stable, and the basic rights and interests after employment are guaranteed. This shows that the overall employment quality of the 2016 graduates is higher.

In the choice of "graduation", 93.8\% of the graduates choose to work, $6.2 \%$ of the graduates choose to learn and other ways. At the same time, $81.8 \%$ of the respondents said they stayed in Shaanxi, of which $62.1 \%$ were distributed in Guanzhong area, $10.2 \%$ were distributed in southern Shaanxi and 9.5\% in northern Shaanxi, which was basically consistent with the initial employment statistics. This shows that the main employment orientation of pre-school education graduates to meet the transformation of the development of local colleges and universities to cultivate the goal of applied talents, in line with its "based in Shaanxi, the service place" position.

The nature of the work unit is relatively stable. $44.3 \%$ of respondents said they were working in government agencies; $16.5 \%$ of respondents said they were working in the "institutions" (mainly kindergarten) Business units; 36.8\% of the respondents work in "other" nature units. This shows that according to the statistics show that graduates tend to choose a relatively stable unit in employment. 
The basic rights and interests after employment are guaranteed. In the survey of "Personnel Relationship Types", 30.2\% of respondents said they had already obtained "formal preparation", $45.5 \%$ of respondents said they were "contract" status, only $11.8 \%$ of respondents said Belong to the "temporary staff", $12.4 \%$ of the respondents chose the "other". This shows that the basic rights and interests of graduates after employment is guaranteed.

The focus on the quality of employment is inseparable from the relationship between the job and the student's degree. During the course of the investigation, the respondents' feedback on "employment related to the profession", 90.1\% of the respondents selected " Yes ", only 9.9\% of the respondents chose" no ". This shows that graduate jobs and professional studies are highly relevant. In the initial employment statistics, $43.75 \%$ of the graduates entered kindergarten, $35.8 \%$ of the graduates entered the work of the institutions related to pre-school education, which basically met the pre-school education professional training program "in pre-school education institutions, early education Institutions, children's cultural career development and other institutions, engaged in teaching, research, management and product development excellence, foundation, ability, high quality, good entrepreneurial application of talent, "the employment target.

During the course of the investigation, $76.5 \%$ of the respondents indicated that they had not changed their work units after employment. $20.0 \%$ of the respondents had changed their work units, $2.7 \%$ of the respondents had changed their work units, and only three working units had been replaced. 5\%. It shows that the pre-school education graduates are more adaptable to the job position, and also shows that the professional personnel training program is more in line with the needs of the pre-school education related work in the course of social development, and the curriculum basically satisfies the needs of the work.

Although according to statistics, pre-school education graduates of the job is better adaptability, but the job satisfaction is still to be improved, in particular, said the current job salary is not satisfactory. $69.8 \%$ of the respondents had an average monthly income of 2000-4000 yuan, while $24.9 \%$ of the respondents had an average monthly income of less than 2,000 yuan. Only $4.1 \%$ of the respondents had an average monthly income of 4,000- 6,000 yuan, while $1.2 \%$ of the respondents "average monthly income" to more than 6,000 yuan. As a result, $75.2 \%$ of respondents said that "if not the main reason for the professional" is due to "low wages."

\section{The employer satisfaction survey}

Employers of the satisfaction of graduates, is an important indicator of the quality of employment evaluation. Some scholars have suggested that the quality of college graduates' employment needs to be evaluated through tripartite satisfaction, mainly as the main body of higher education needs of the government, students and employers [7]. Therefore, in the first graduates employment nearly a year, pre-school in May 2017 period, for graduates in the work of the employer to carry out a comprehensive questionnaire survey. The questionnaire covers a total of 19 major issues such as "the basic situation of the unit", "general requirements for graduates", "comprehensive evaluation of graduates", "evaluation of graduates' professional accomplishment", "opinions and suggestions" The The "level of satisfaction" is based on the "level of satisfaction", "satisfaction", "general" and "dissatisfied". In order to take into account the professional characteristics of pre-school education, the questionnaire designed the "kindergarten teacher professional standards" as the basis of the employer to the graduates "professional philosophy and ethics", "professional knowledge", "professional ability" evaluation project. 150 questionnaires were sent to the survey, and 136 valid questionnaires were collected. The recovery rate was $90.6 \%$. According to the survey results found:

136 units accounted for $14.7 \%$, business (state-owned, private) units accounted for $82.4 \%$, other units accounted for 2.9\%; 23 units in the size of 50 people, 49 units in the scale of 50-100, 35 Unit size in more than 200 people. In the participating units, the existing professional graduates 1-5 people accounted for $38.2 \%$, now I am professional graduates $5-10$ people accounted for $11.8 \%$, in addition to $24.3 \%$ of the existing units of my professional graduates more than 10 people The This also proves that my professional graduates in the employer has a good reputation and demonstration 
effect, to attract employers continue to absorb the employment of graduates.

In the overall evaluation of graduates, the employer is very important to its "professional ability", combined with the characteristics of pre-school education, "kindergarten teacher professional standards" as the basis, from the "professional philosophy and ethics", "professional knowledge" "Professional ability" targeted to the employer conducted a survey.

Employers 'overall evaluation of graduates' professional accomplishment is higher. The results show that the evaluation of the four-level scale in the 14 dimensions of the three dimensions of the graduates' professional accomplishment focuses on the "satisfaction" and "satisfactory" options, of which 11 are "General" evaluation within 10\%, "dissatisfied" evaluation is zero. This shows that after years of efforts by pre-school, graduates of professional literacy basically meet the requirements of personnel training objectives.

Graduates of professional ideas and teachers to obtain a higher evaluation. In the "professional philosophy and ethics" evaluation dimension, pre-school education graduates get a higher evaluation, employers in the "very satisfied" and "more satisfied" on the evaluation of the two total more than 95\%. This shows that pre-school education in the process of personnel training, to better achieve the training objectives of the "professional training with good ideological and moral qualities, love pre-school education, solid pre-school education expertise and skills" requirements.

Graduates conservation, education ability is more prominent. In the process of horizontal comparison of three evaluation dimensions, the employer for the pre-school education graduates "teaching ability" to give a high evaluation. Among them, in the professional concept and ethics dimension, "attitude and behavior of early childhood care and education" (95.7\% more satisfaction); professional knowledge in the "early childhood care and education knowledge" (more satisfied with the above accounted for 93.2\%); Capacity in the "one day life and conservation" (more satisfied with the above accounted for 92\%) are given a higher rating. This also shows that pre-school education in the process of personnel training, to better achieve the training objectives "to be competent and engaged in pre-school education institutions, teaching and research, as well as children's cultural career development work practice of the general-style pre-school Education talent.

Graduates have a good ability to communicate with their children. Throughout the three evaluation dimensions, the employer on the pre-school education graduates and children's ability to communicate also affirmed. For example, in the professional concept and ethics, "the attitude and behavior of children" (more satisfied with the above accounted for 99.2\%); professional knowledge in the "knowledge of early childhood development" (more satisfied with the above accounted for 93.2\%); professional competence dimension "Communication and cooperation" (more satisfied with the above accounted for 93.2\%) also give a higher rating.

Through this survey, we learned a lot of valuable advice and suggestions from employers, of which $41.5 \%$ of the units suggested that pre-school education students need to strengthen the "innovation ability" of the training, in line with the previous research situation; at the same time $30 \%$ Also suggested that pre-school education graduates in the actual work is more lack of "professional skills (including bombs, singing, jumping, painting, hand, etc.)." In the future training program of personnel training process, pre-school professional will seriously consider the views of employers and suggestions.

As a reform and development of local colleges and universities, the first graduate of pre-school education graduates for the smooth employment of pre-school education in Shaanxi Province into the development of new forces, although there are still some deficiencies in the employment work, still cannot make up for the gap of pre-school teachers, But for the training of kindergarten teachers and the mechanism of continuous improvement has accumulated valuable experience.

\section{Acknowledgments}

This study is the key project of "Research on the Training System of Excellence Kindergarten Teachers" (15JG001Z), a key project of teaching reform research in Shaanxi Xueqian Normal University. 


\section{References}

[1] Li Genmin, Wang Yuequn, Yu Ling, Su Xiaofen. Investigation Report on the Development of Preschool Education in Shaanxi Province [A]. Department of Basic Education, Shaanxi Provincial Department of Education, 2011, 4

[2] Shaanxi Development and Reform Planning [2011] 892 document.

[3] Yao Jianguo. Pre-school teachers in Shaanxi Province analysis [J]. New West, 2011 (33): 24.

[4] Wang Ting, Zhang Ting. Expand the employment strategy under the background of China's college students employment quality research [J]. China Higher Education Research, 2014 (2): 26-30

[5] Lingyun, Yang Heqing. The Impact of Economic Crisis on Labor Relations Management and Its Countermeasures [J]. Economics and Management Research, 2010 (03): 118-122.

[6] Zhang Yaoxiang. Based on the tripartite satisfaction of college graduates employment quality evaluation research [J]. China Higher Education Research, 2013 (5): 82-86. 